\title{
$\mathrm{M}|\mathrm{R}| \mathrm{S}$ Internet Journal Nitride Semiconductor Research
}

\section{Growth and Device Performance of GaN Schottky Rectifiers}

\author{
Jen-Inn Chyi ${ }^{1}$, C. -M. Lee ${ }^{1}$, C.C.Chuo ${ }^{1}$, G. C. Chi ${ }^{2}$, G. T. Dang ${ }^{3}$, A. P. Zhang ${ }^{3}$, Fan Ren ${ }^{3}$, X.A. \\ $\mathrm{Cao}^{4}$, S.J. Pearton ${ }^{4}$, S. N. G. $\mathrm{Chu}^{5}$ and R. G. Wilson ${ }^{6}$ \\ ${ }^{1}$ Department of Electrical Engineering,National Central University,Taiwan, \\ ${ }^{2}$ Department of Physics, National Central University, \\ ${ }^{3}$ Department of Chemical Engineering, University of Florida, \\ ${ }^{4}$ Department of Materials Science and Engineering, University of Florida, \\ ${ }^{5}$ Bell Laboratories, Lucent Technologies, \\ ${ }^{6}$ Consultant,Stevenson Ranch, CA,
}

(Received Monday, June 21, 1999; accepted Thursday, August 19, 1999)

Undoped, $4 \mu \mathrm{m}$ thick GaN layers grown by Metal Organic Chemical Vapor Deposition were used for fabrication of high stand off voltage $(356 \mathrm{~V})$ Schottky diode rectifiers. The figure of merit $\mathrm{V}_{\mathrm{RB}}{ }^{2} /$ $\mathrm{R}_{\mathrm{ON}}$, where $\mathrm{V}_{\mathrm{RB}}$ is the reverse breakdown voltage and $\mathrm{R}_{\mathrm{ON}}$ is the on-resistance, was $\sim 4.53 \mathrm{MW}$ $\mathrm{cm}^{-2}$ at $25^{\circ} \mathrm{C}$. The reverse breakdown voltage displayed a negative temperature coefficient, due to an increase in carrier concentration with increasing temperature. Secondary Ion Mass Spectrometry measurements showed that $\mathrm{Si}$ and $\mathrm{O}$ were the most predominant electrically active impurities present in the GaN.

\section{Introduction}

There is strong interest in the development of efficient switches operating in the power ranges between 100 $\mathrm{kW}-1 \mathrm{MW}$ and well above $1 \mathrm{MW}$. [1] [2] In the former category the applications include improved control over power distribution on the electricity grid, and electrical sub-systems in electric automobiles, advanced aircraft ships and combat vehicles. An important need is for high efficiency, lightweight, $\sim 100 \mathrm{~kW}$ dc-to-ac inverters to drive the ac induction motors for propulsion and dcto-dc converters for storage-to-bus energy conversion. [1] [2] In the latter category is improved transmission and control of electric power by the utilities industry. It is anticipated that the packaged semiconductor switches will need to operate at temperatures in excess of $250^{\circ} \mathrm{C}$ without liquid cooling. [1] [2] [3] [4] For these high temperature, high power applications the wide bandgap semiconductors offer many advantages. While $\mathrm{SiC}$ is the leading candidate for these switches because of its more mature growth and processing technology [4] [5] [6] [7] [8] [9] [10] [11] [12] [13] [14] [15] (Al)GaN is also of interest for these applications because of its larger bandgap and excellent transport properties. [1] [4] [6]

One of the baseline devices in power switching is the thyristor. The combination of a thyristor, power diode and appropriate packaging produces an inverter module.
Schottky barrier diodes are employed as high-voltage rectifiers in power switching applications. They can be turned-off faster than junction diodes because of the absence of minority carrier storage effects and there is negligible power dissipation during switching. [5] [7] [8] There have been numerous reports of SiC Schottky diode rectifiers, some employing edge termination techniques to avoid field crowding at the edge of the metal contact, [16] [17] [18] [19] [20] [21] [22] [23] [24] [25] with blocking voltages up to $\sim 3 \mathrm{kV}$. [13] The corresponding blocking voltage for the best $p-n$ junction diode in $\mathrm{SiC}$ is $\sim 5.5 \mathrm{kV}$. [24]

Much less work has been done in $\mathrm{GaN}$. Bandic et.al. [26] fabricated $450 \mathrm{~V}$ Schottky rectifiers on $8-10 \mu \mathrm{m}$ thick layers grown by hydride vapor phase epitaxy (HVPE). The doping in the layer was $\sim 2 \times 10^{16} \mathrm{~cm}^{-3}$. Later they reported achievement of $750 \mathrm{~V}$ devices on a multi-growth structure consisting of $8 \mu \mathrm{m}$ of HVPE GaN, [27] followed by $3 \mu \mathrm{m}$ of undoped GaN grown by Metal Organic Chemical Vapor Deposition (MOCVD). A drawback of the HVPE appears to be fairly non-uniform electrical properties with the diode breakdown voltages varying by almost a factor of two. [26]

In this paper we report on the MOCVD growth of relatively thick ( $\sim 5 \mu \mathrm{m}$ total) GaN layers for high breakdown applications and on the elevated temperature per- 
formance of Schottky diode rectifiers fabricated on this material. We find that the reverse breakdown voltage $\left(\mathrm{V}_{\mathrm{RB}}\right)$ in our diodes has a negative temperature coefficient (i.e. decreases with increasing temperature).

\section{Experimental}

The GaN sample studied in this work was grown on cplane sapphire by low-pressure metalorganic chemical vapor deposition in a horizontal reactor. Ammonia $\left(\mathrm{NH}_{3}\right)$, trimethylgallium (TMG) and silane $\left(\mathrm{SiH}_{4}\right)$ were used as precursors and dopants, respectively. A twostep growth method was used to obtain GaN films with smooth surfaces. A low temperature $\mathrm{GaN}$ nucleation layer of about $220 \mathrm{~nm}$ was first grown at $460^{\circ} \mathrm{C}$ after heating of the substrate at $1050^{\circ} \mathrm{C}$ in hydrogen ambient for 10 minutes. Then the substrate temperature was raised to $1050^{\circ} \mathrm{C}$ for the growth of the $1 \mu \mathrm{m}$ thick Sidoped $\left(3 \times 10^{18} \mathrm{~cm}^{-3}\right)$ and $4 \mu \mathrm{m}$ thick undoped GaN layers. The growth rate of high temperature $\mathrm{GaN}$ was $1.5 \mu \mathrm{m} / \mathrm{hr}$, while that for the nucleation layer was about $0.3 \mu \mathrm{m} / \mathrm{hr}$.

The samples were characterized by cross-sectional Transmission Electron Microscopy (TEM) and Secondary Ion Mass Spectrometry (SIMS) to examine crystalline quality and impurity background, respectively. The surface roughness was measured by tapping mode Atomic Force Microscopy (AFM). Lateral, planar diodes were fabricated using lift-off of e-beam deposited $\mathrm{Ni}(500 \AA) / \mathrm{Au}(2000 \AA)$ for rectifying contacts and $\mathrm{Ti}(500 \AA) / \mathrm{Au}(2000 \AA)$ for ohmic contacts.

\section{Results and Discussion}

Figure 1 shows some cross-section TEM pictures of the as-grown structure taken in different contrast conditions to show the various defects present. In the top part of the figure it is seen that the average spacing between threading dislocations at the surface is roughly $1 \mu \mathrm{m}$, corresponding to a density of $\sim 10^{8} \mathrm{~cm}^{-2}$. In the lower part of the figure we show a higher magnification view of the $\mathrm{GaN} / \mathrm{Al}_{2} \mathrm{O}_{3}$ interfacial region. The arrows indicate defects that bend and do not propagate to the surface. Note that there is no visible demarcation between the Si-doped and undoped $\mathrm{GaN}$ regions.

Figure 2 shows AFM scans taken over $1 \mathrm{x} 1 \mu \mathrm{m}^{2}$ and $10 \times 10 \mu \mathrm{m}^{2}$ areas. The root-mean-square (RMS) roughnesses are very good in both cases $(0.22$ and $1.6 \mathrm{~nm}$, respectively). On HVPE material of similar thickness, we typically observe RMS values 5-10 times larger than on MOCVD material. This may have important consequences for other power devices such as Metal-OxideSemiconductor Field Effect Transistors (MOSFETs) where carrier transport is strongly influenced by the quality of the oxide-semiconductor interface.
SIMS profiles of $\mathrm{H}, \mathrm{O}, \mathrm{Si}$ and $\mathrm{C}$ in the $\mathrm{GaN}$ are shown in Figure 3. The carbon concentration is at the background sensitivity level of the SIMS instrument under these conditions $\left(\sim 10^{17} \mathrm{~cm}^{-3}\right)$, while the $\mathrm{H}, \mathrm{O}$ and $\mathrm{Si}$ are above the detection limits $\left(2 \times 10^{17}, 10^{17}\right.$ and $3 \times 10^{16} \mathrm{~cm}^{-3}$, respectively). The residual hydrogen presumably originates from the growth precursors, all of which contain hydrogen while $\mathrm{Si}$ and $\mathrm{O}$ are the typical background impurities detected in epitaxial GaN. [28] These can originate from the precursors (oxygen is a common impurity in ammonia) or from quartzware within the reactor. The concentrations of these impurities is typical of very high quality GaN. [28]

Figure 4 shows a schematic of the planar diodes fabricated on the thick GaN layers. Circular Schottky contacts with diameters $60-1100 \mu \mathrm{m}$ were employed. The on-resistance of the diodes can be generally improved by etching a mesa structure to place the ohmic contacts on the $\mathrm{n}^{+}$buffer layers, but this has also been reported to decrease $V_{R B}$ through introduction of dry etch damage on the mesa sidewalls. [26] In our case we found mesa structures showed similar reverse breakdown voltages to planar diodes if we annealed the samples at $\sim 750^{\circ} \mathrm{C}$ under $\mathrm{N}_{2}$ after dry etching in order to remove the etch damage.

Figure 5 shows a typical current-voltage (I-V) characteristic at $25^{\circ} \mathrm{C}$ from one of the diodes. The $\mathrm{V}_{\mathrm{RB}}$ is $\sim 356 \mathrm{~V}$ at this temperature. The barrier heights were $\sim 1 \mathrm{eV}$ for the Ni contracts, with ideality factors typically of 1.4-1.6. Capacitance-voltage measurements confirmed the free electron concentration of $\sim 2 \times 10^{16} \mathrm{~cm}^{-3}$. At $25^{\circ} \mathrm{C}$ the on-voltage was $\sim 3.5 \mathrm{~V}$ for a current density of $100 \AA \mathrm{cm}^{-2}$. This is slightly lower than that achieved previously on thicker epi layers. The figure-of-merit $\mathrm{V}_{\mathrm{RB}} / \mathrm{R}_{\mathrm{ON}}$ had a value $\sim 4.53 \mathrm{MW} \cdot \mathrm{cm}^{-2}$. The best reported high breakdown diodes in $\mathrm{SiC}$ have values in the range $265-528 \mathrm{MW} \cdot \mathrm{cm}^{-2}$. [11] [13]

To place our results in context, Figure 6 shows a plot of calculated avalanche breakdown voltages in $\mathrm{GaN}$ Schottky diodes, as a function of epi thickness and doping. It is clear that both in this current work and that from the Caltech group. [26] [27] the breakdown voltages are still well below the expected theoretical values. Improvements in both materials and processing, especially surface passivation and edge termination techniques are needed to fully realize the capabilities of GaN high power electronics.

Several groups have reported measurements of the temperature dependence of the breakdown field in $\mathrm{GaN}$ devices. In GaN/AlGaN heterostructure field effect transistors, Dyakonova et.al. [29] found a positive tem- 
perature coefficient for the breakdown of $\sim 0.33 \mathrm{~V} \cdot \mathrm{K}^{-1}$. Dmitriev et.al. [30] also found a positive temperature coefficient for breakdown in $\mathrm{p}^{+} \mathrm{pn}^{+}$diodes, with a value $0.02 \mathrm{~V} \cdot \mathrm{K}^{-1}$. Osinsky et.al. [31] reported a value of $+0.0008 \mathrm{~V} \cdot \mathrm{K}^{-1}$ in $\mathrm{p}$-i-n diodes. In these cases the breakdown mechanism is avalanche due to impact ionization. [32] In some SiC Schottky diodes, a negative temperature coefficient is found. [5] In these cases, the breakdown mechanism is defect-assisted tunnelling through surface or bulk states. [32]

Figure 7 shows the temperature dependence of $\mathrm{V}_{\mathrm{RB}}$ in our diodes. The breakdown voltage decreases with increasing measurement temperature, but the decrease is not linear. The temperature coefficient is $-0.92 \mathrm{~V} \cdot \mathrm{K}^{-}{ }^{1}$ in the range $25-50^{\circ} \mathrm{C}$ and $0.17 \mathrm{~V} \cdot \mathrm{K}^{-1}$ in the range 50 $150^{\circ} \mathrm{C}$. In a simplistic picture, the breakdown voltage scales with the fourth power of the bandgap $\mathrm{E}_{\mathrm{g}}$. [22] [32] The bandgap of $\mathrm{GaN}$ has a negative temperature coefficient, variously reported between $0.39-0.67$ $\mathrm{meV} \cdot \mathrm{K}^{-1}$. [33] [34] [35] (Monemar [36] gave a more precise relation, $\mathrm{E}_{\mathrm{g}}=3.503+\left(5.08 \times 10^{-4} \mathrm{~T}^{2}\right) / \mathrm{T}-996$, where $T$ is the temperature in degrees Kelvin). Therefore, $\mathrm{V}_{\mathrm{RB}}$ would decrease with increasing temperature in this model. However, in our diodes we see an increase of approximately a factor 3 in free electron concentration from $25-150^{\circ} \mathrm{C}$ as measured by $\mathrm{C}-\mathrm{V}$, which will reduce $V_{R B}$. This effect is larger than the effect of the decrease in electron energy as temperature increases, and thus $\mathrm{V}_{\mathrm{RB}}$ decreases at high temperature rather than increasing as would be the case if impact ionization were the cause of breakdown. The reverse saturation current (measured at $-100 \mathrm{~V}$ ) also increases with temperature, as shown in Figure 8. This current scaled in proportion to the square of the diode diameter, suggesting that it originated from the area under the contact and not from the periphery, i.e. was related to the bulk properties of the $\mathrm{GaN}$.

\section{Summary and Conclusions}

Thick, undoped GaN layers grown by MOCVD show promise for high breakdown Schottky diode rectifiers. The main potentially active impurities detected by SIMS measurements are $\mathrm{Si}$ and $\mathrm{O}$, but only a fraction of these contribute to the background carrier concentration of $\sim 2 \times 10^{16} \mathrm{~cm}^{-3}$ at room temperature. The surfaces of the $\mathrm{GaN}$ are quite smooth (RMS roughness of $1.6 \mathrm{~nm}$ measured over $10 \times 10 \mu \mathrm{m}^{2}$ ) and threading dislocation densities are of order $10^{8} \mathrm{~cm}^{-2}$ at the surface of structures with total thickness $5 \mu \mathrm{m}$. Revere breakdown voltages of $356 \mathrm{~V}$ were obtained at room temperature, which are about a factor of 3 lower than the theoretical maximum.
In our diodes the breakdown voltage decreases with increasing temperature, due primarily to an increase in carrier concentration. It is expected that significant improvements in breakdown voltage can be obtained with better edge termination and surface passivation methods, and by the use of implantation to produce $\mathrm{n}^{+}$ surface contact regions.

\section{ACKNOWLEDGMENTS}

The work at UF is partially supported by a DARPA/ EPRI grant (D. Radack/J. Melcher), no. MDA 07298-1-006, monitored by ONR (J.C. Zolper). The work at $\mathrm{NCU}$ is sponsored by a National Council of ROC under contract no. NSC-88-2215-E-008-012. The work of RGW is partially supported by a grant from ARO (J. M. Zavada).

\section{REFERENCES}

[1] E. R. Brown, Sol. St. Electr. 42, 2117 (1998).

[2] G. T. Heydt, B. J. Skromme, Mater. Res. Soc. Symp. Proc. 483, 3 (1998).

[3] M. Trivedi, K. Shenai, J. Appl. Phys. 85, 6889 (1999).

[4] C. E. Weitzel, J. W. Palmour, C. H. Carter, K. Moore, K. J. Nordquist, S. Allen, C. Thero, M. Bhatnagar, IEEE Trans. Electr. Dev. 43, 1732 (1996).

[5] G. Kelner, M. Shur, in Properties of SiC, ed. G.L. Harris, EMIS Data Review 13 (INSPEC, IEE, London 1995)

[6] J. C. Zolper, Sol. St. Electr. 42, 2153 (1998).

[7] B. J. Baliga, Power Semiconductor Devices (ITP Publishers, Boston 1996)

[8] C. I. Harris, A. O. Konstantinov, Phys. Scr. T79, 27 (1999).

[9] M. Bhatnagar, B. J. Baliga, IEEE Trans. Electr. Dev. 40, 645 (1993).

[10] J. N. Shenoy, M. R. Melloch, J. A. Cooper, IEEE Electron Dev. Lett. 18, 93 (1997).

[11] K. J. Shoen, J. M. Woodall, J. A. Cooper, M. R. Melloch, IEEE Electron Dev. Lett. 45, 1595 (1998).

[12] J. Spitz, M. R. Melloch, J. A. Cooper, M. A. Capano, IEEE Electron Dev. Lett. 19, 100 (1998).

[13] F. Dahlquist, C. M. Zetterling, M. Östling, K. Rottner, Mater. Sci. Forum 264-268, 1061 (1998).

[14] J. B. Casady, A. K. Agarwal, S. Seshadri, R. R. Siergiej, L. B. Rowland, M. MacMillan, D. C. Sheridan, P. A. Sanger, C. D. Brandt, Sol. St. Electr. 42, 2165 (1998).

[15] A. K. Agarwal, J. B. Casady, L. B. Rowland, W. F. Valek, C. D. Brandt, Mater. Sci. Forum 264-268, 989 (1998).

[16] J.A. Edmond, H.S. Kong, C.H. Carter, "advances in SiC power electronics", Proc. 4th Int. Conf. Amorphous and Cryst. $\mathrm{SiC}$, ed. C.Y. Yang, M.M. Rahman and G.L. Harris (SpringerVerlag, Berlin, Germany, 1992), pp. 344-351

[17] L. G. Matus, J. A. Powell, Appl. Phys. Lett. 59, 1770 (1991).

[18] P. G. Neudeck, D. J. Larkin, C. S. Salupo, J. A. Powell, L. G. Matus, Inst. Phys. Conf. Ser. 137, 51 (1994).

[19] M. Glezzo, D. M. Brown, E. Downey, J. Kretchmer, J. J. Kopansky, Appl. Phys. Lett. 63, 1206 (1993). 
[20] J.W. Palmou, J.A. Edmond, H.S. Kong, C.H. Carter, "recent advances in SiC power electronics", Proc. 5th Int. Conf. SiC and Related Materials, ed. M.G. Spencer (IOP Publishing, Bristol, UK, 1994), pp. 499-502

[21] T. Urushidani, T. Kimoto, H. Matsunami, "performance of SiC diodes for high power", Proc. 5th Int. Conf. SiC and Related Materials, ed. M.G. Spencer (IOP Publishing, Bristol, UK, 1994), pp. 471-474

[22] J.H. Zhao, K.Z. Xie, W. Buchwald, J.R. Flemish, "high quality SiC power rectifiers", Proc. 5th Int. Conf. SiC and Related Materials, ed. M.G. Spencer (IOP Publishing, Bristol, UK, 1994), pp. 11-14

[23] Itoh, T. Kimoto, H. Matsunami, Inst. Phys. Conf. Ser. 142, 689 (1996).

[24] K. G. Irvine, R. Singh, M. J. Paisley, J. W. Palmour, O. Kordina, C. H. Carter, Mater. Res. Soc. Symp. Proc. 512, 119 (1998).

[25] O. Kordina, J. P. Bergman, A. Henry, E. Janzen, S. Savage, J. Andre, L. P. Ramberg, U. Linefelt, W. Hermensson, K. Bergman, Appl. Phys. Lett. 67, 1561 (1995).
[26] Z. Z. Bandic, P. M. Bridger, E. C. Piquette, T. C. McGill, R. P. Vaudo, V. M. Phanse, J. M. Redwing, Appl. Phys. Lett. 74, 1266 (1999).

[27] Z. Z. Bandic et al. (unpublished)

[28] S. J. Pearton, J. C. Zolper, R. J. Shul, F. Ren, J. Appl. Phys. 86, R1 (1999).

[29] N. Dyakonova, A. Dickens, M. S. Shur, R. Gaska, J. W. Yang, Appl. Phys. Lett. 72, 2562 (1998).

[30] V. A. Dmitriev, K. G. Irvine, C. H. Carter, Jr., N. I. Kuznetsov, E. V. Kalinina , Appl. Phys. Lett. 68, 229-231 (1996).

[31] A. Osinsky, M. S. Shur, R. Gaska, Mater. Res. Soc. Symp. Proc. 512, 15 (1998).

[32] SM Sze, Physics of Semiconductor Devices , (Wiley, New York, 1981), .

[33] D. L. Camphausen, G. A. N. Connell, J. Appl. Phys. 42, 4438 (1971).

[34] J. I. Pankove, S. Bloom, G. Harbeke, RCA Rev. 36, 163 (1975).

[35] E. Kauer, A. Rabenau, Z. Nat. Forsch. A12, 942 (1959).

[36] B. Monemar, Phys. Rev. B 10, 676 (1974). 


\section{FIGURES}
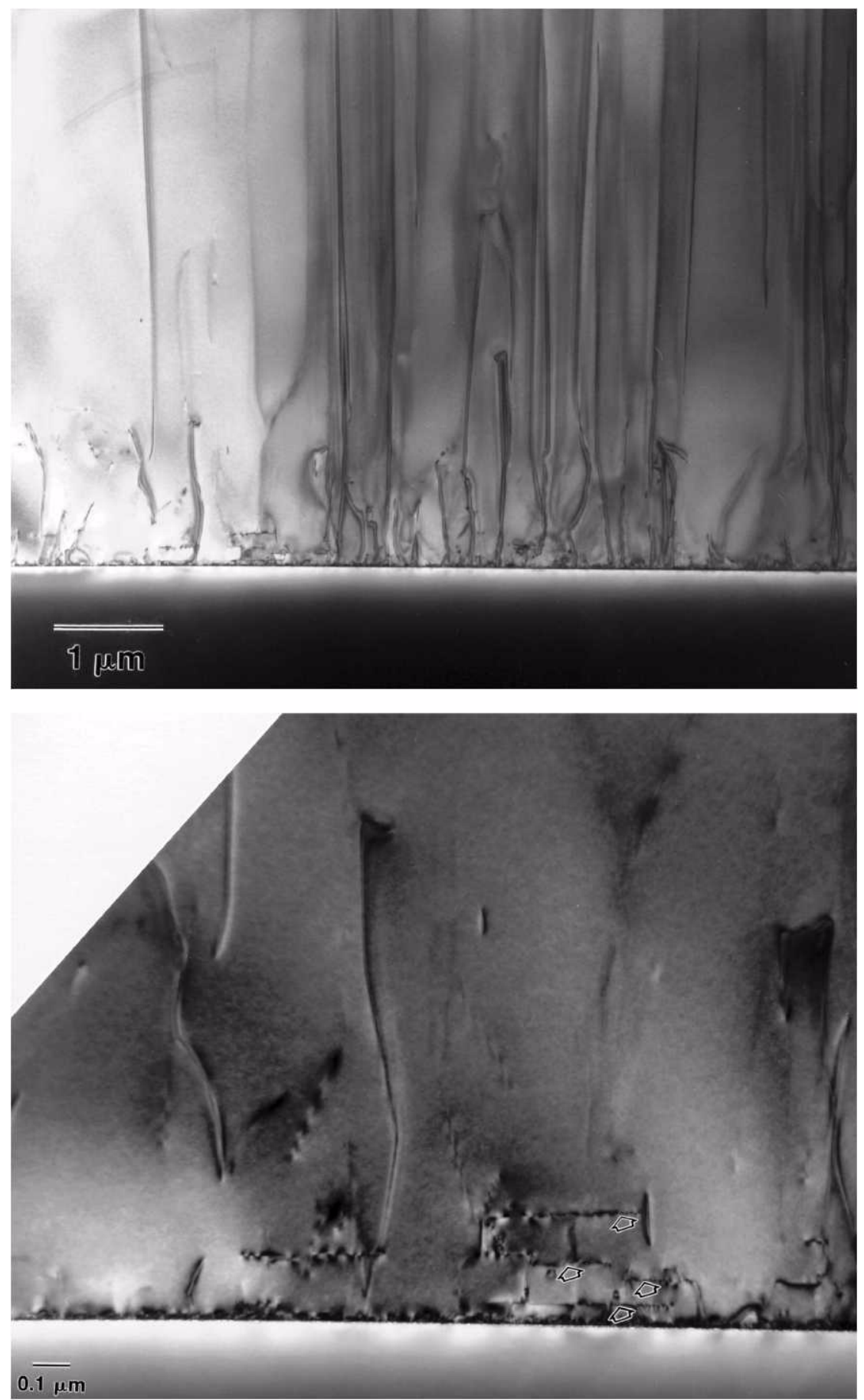

Figure 1. Cross-sectional TEM micrographs of MOCVD grown $\mathrm{GaN}$ on $\mathrm{Al}_{2} \mathrm{O}_{3}$ substrates. 


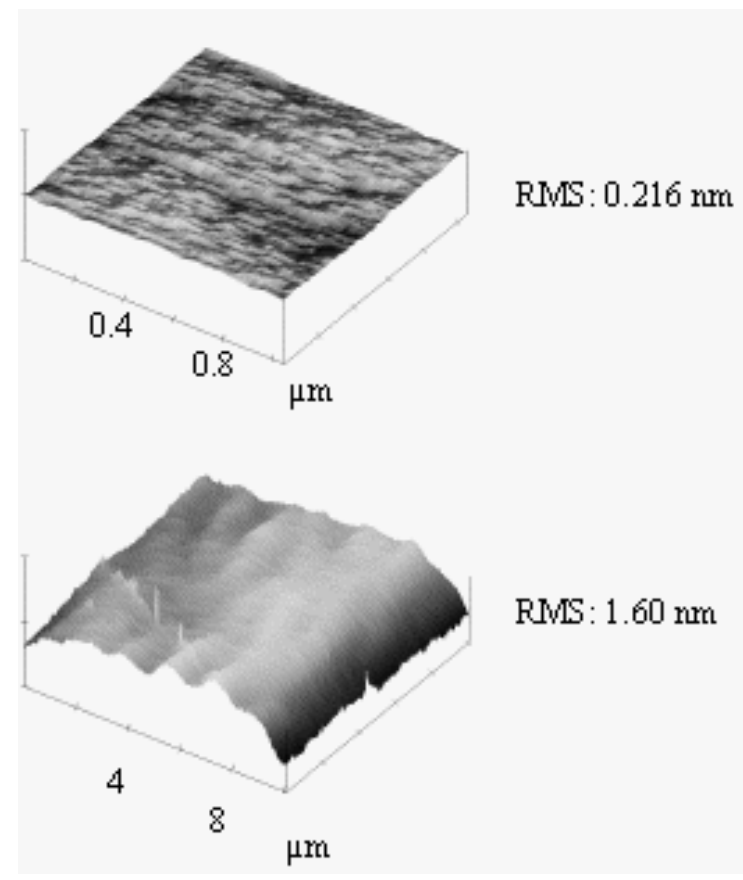

Figure 2. AFM scans of GaN surface for areas of $1 \mathrm{x} 1 \mu \mathrm{m}^{2}$ (top) or $10 \mathrm{x} 10 \mu \mathrm{m}^{2}$ (bottom).

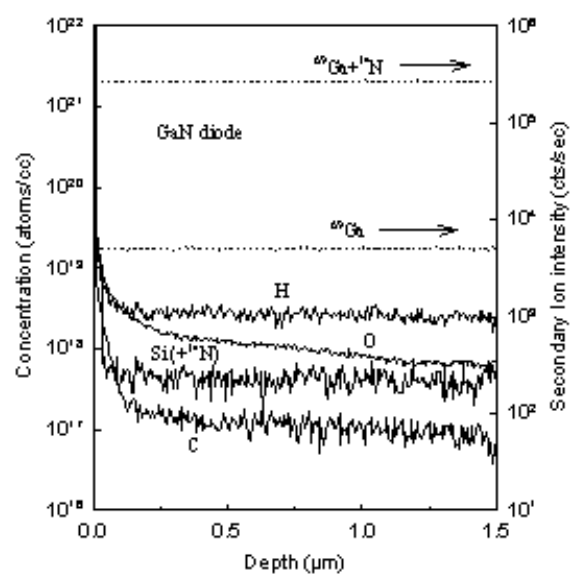

Figure 3. SIMS profiles of $\mathrm{O}, \mathrm{C}, \mathrm{H}$ and $\mathrm{Si}$ in upper $1.5 \mu \mathrm{m}$ of the $\mathrm{GaN}$ epilayer.

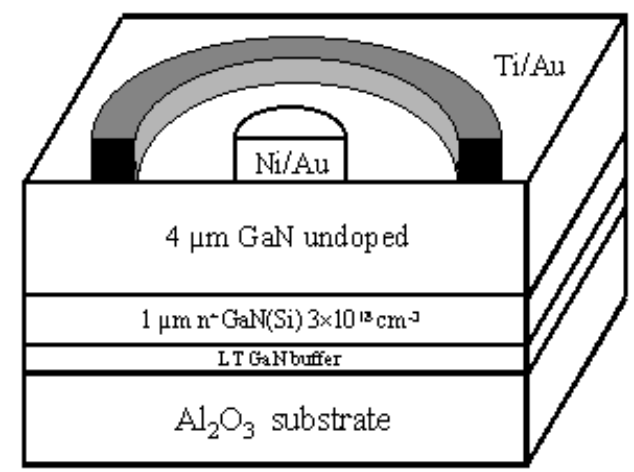

Figure 4. Schematic of GaN planar Schottky diode.

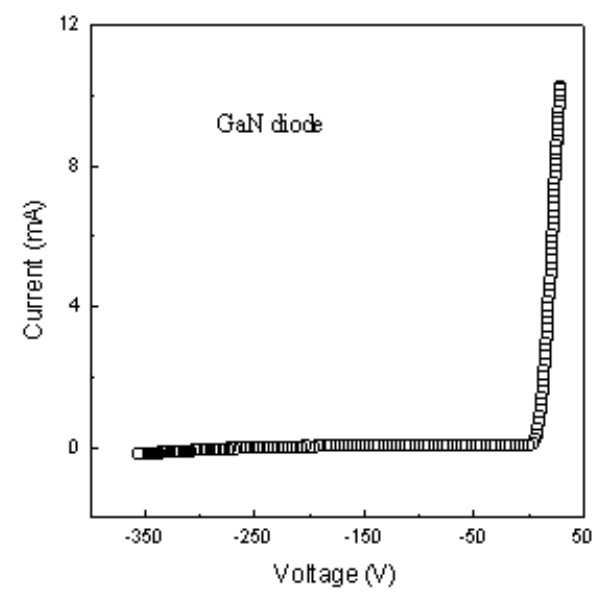

Figure 5. I-V characteristic at $25^{\circ} \mathrm{C}$ of GaN Schottky diode.

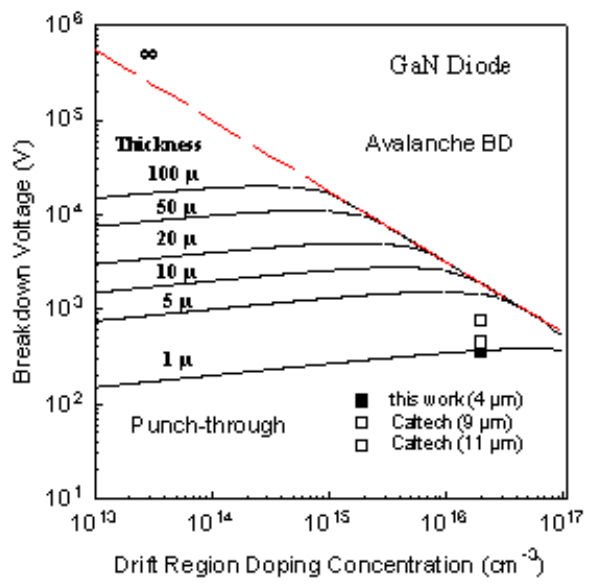

Figure 6. Calculated breakdown voltage as a function of doping and epi thickness in GaN Schottky diodes. Experimental points from Caltech work [26] and this work are also shown. 


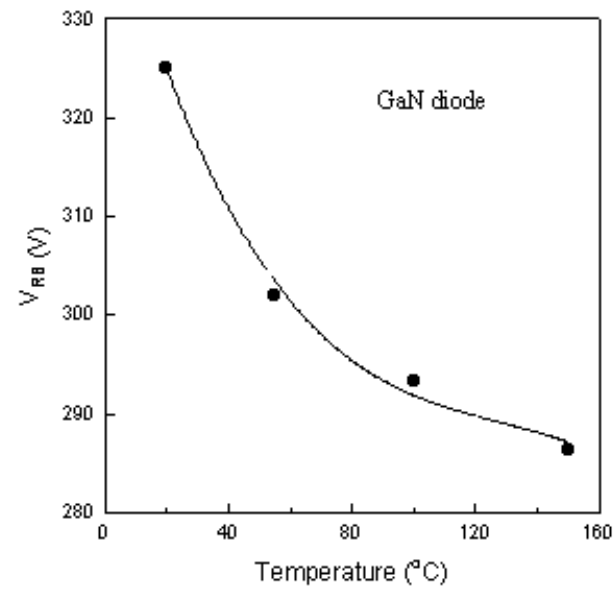

Figure 7. Measurement temperature dependence of $\mathrm{V}_{\mathrm{RB}}$ in GaN Schottky diodes.

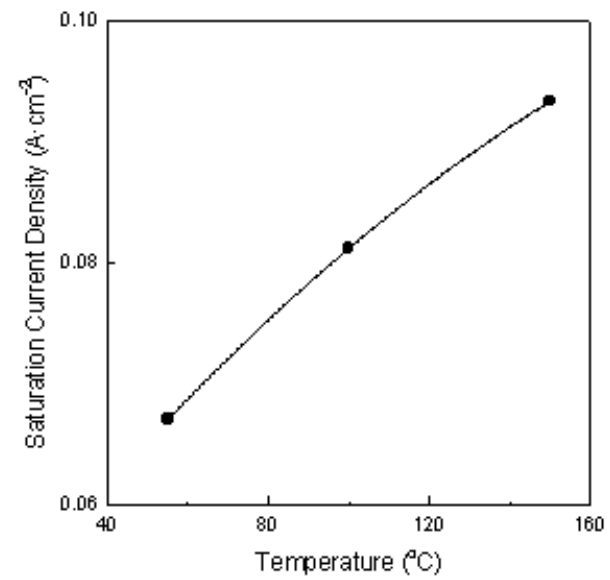

Figure 8. Measurement temperature dependence of reverse saturation current density measured at $-100 \mathrm{~V}$ bias. 